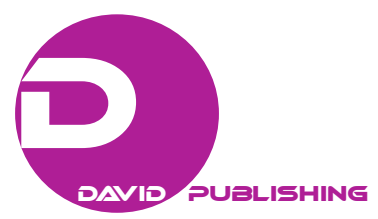

\title{
Sustainable Data Analytics for Environmental Performance Monitoring in Dynamic Supply Chain Infrastructure
}

\author{
Eugene Wong \\ Hang Seng Management College, Hong Kong, China \\ Tony Wines, Serena Li \\ Turnkey Group Limited, Hong Kong, China
}

\begin{abstract}
The increase in climate change raises the awareness of societal stakeholders to act as key-drivers in motivating and pushing corporations to monitor their sustainability data transparency, analyse their operations performance, and improve their operations related to environment, social governance, and corporate social responsibility. This paper evaluates the current importance of the societal stakeholders that impact the compliance of companies towards these environmental, social and governance practices in their supply chain operations. The latest review on the sustainability reporting and its data analytics are carried out, followed by a review of the development of a sustainability reporting and data analytics model, including sustainability software and online platforms in facilitating and supporting supply chain practitioners in their decision-making process. The model has been further developed as a dashboard and applied to a maritime supply chain firm. A case analysis has been conducted to illustrate the importance of analytics data in supporting complex decision-making process. Additional intelligent data analytics functionalities are recommended as future development for the sustainability reporting and data analytics dashboard in supply chain operations.
\end{abstract}

Keywords: sustainability reporting, supply chain management, global reporting initiative, corporate social responsibility

\section{Introduction}

The increase in climate change awareness is compelling companies to transition shift away from the more traditional "business-as-usual" operations to encompass sustainability along the supply chain as part of their corporate scheme. More importantly, societal stakeholders, defined here as sustainability verification bodies, government, non-governmental organizations (NGOs), stock exchanges, and shareholders, are demanding higher transparency and accountability on a company's data analytics and reporting related to environmental, social governance (ESG), corporate social responsibility (CSR), and sustainability. In recent times, the rise of

Acknowledgement: The work described in this paper was partially supported by a grant from the Research Grants Council of the Hong Kong Special Administrative Region, China (UGC/FDS14/B16/16).

Eugene Wong, assistant professor, Department of Supply Chain and Information Management, School of Decision Sciences, Hang Seng Management College, Hong Kong, China.

Tony Wines, CEO and Founder, Turnkey Group Limited, Hong Kong, China.

Serena Li, senior project manager, Turnkey Group Limited, Hong Kong, China.

Correspondence concerning this article should be addressed to Eugene Wong, Hang Shin Link, Siu Lek Yuen, Shatin New Territories, Hong Kong, China. 
financial institutions including sovereign funds, limited partners, institutional investment, and private equity has increased pressure to provide analytical evidence of good sustainability performance, as part of the due diligence process to fulfill ethical investment requirements in the market. This has further accelerated and improved sustainable practices and analytics among companies which require financing and investment.

At the forefront of this changing economic environment, business strategies have been refined, allowing leading businesses and multinationals to embrace practices that incorporate focus not only on the financial elements but also the environmental and social aspects. It is now critical for companies to succeed in managing their sustainability impact in correlation with financial growth. This measurement of a company's sustainability performance through evaluating environmental, social, and economic aspects, is known as the "Triple Bottom Line”, which is increasingly important as companies engage in both ethical and sustainable strategies that will define their brand and role in managing leading sustainable practices in the future.

Managing the collection of data to monitor and benchmark performance as well as achieving corporate goals in sustainability is complex. Conducting detailed assessments in the supply chain is even more sophisticated as companies struggle to successfully capture data from suppliers, shippers, manufacturers, and external parties. In effect, there are a growing number of companies that seek decision support tools to present data analytics and address the precise issues of data consolidation and management across their network supply chains. This paper argues that as a result of societal pressures, businesses are required to become more holistic in their approach to operational management by considering their supply chain through a triple bottom line perspective, and should recognize the benefits of software and online platform solutions as a decision-support tool which aids the process of achieving measurable sustainability goals.

The objective of this paper is two-fold. First, the paper aims to determine the importance of societal stakeholders that impacts a company's compliance towards incorporating environmental, social and governance practices in their operations across the supply chain in forms of data analytics and sustainability reporting. Second, the paper highlights the role of sustainability related decision-support online tools to help companies manage, measure, and report on their sustainability performance through quantifiable and measurable means, i.e. via data analytics. Overall, this paper focuses on contributing to the literature regarding long-term and sustainable business processes as well as the increasingly role of software as a decision-support tool in areas for sustainability.

\section{The Role of Stakeholders in Sustainability Reporting and Data Analytics Along the Supply Chain}

This section will first provide a general overview of the stakeholders that affect businesses corporate sustainability strategy and examine existing literature on the impacts and benefits of data analytics and sustainability reporting along the supply chain. Who are the stakeholders that put pressure on companies to invest in the triple bottom line perspective? The increasing levels of external governing bodies that require detailed evaluations of a company's supply chain exacerbate the need for companies to enhance the reporting structure. To manage a sustainable supply chain effectively, companies are required to focus on a multitude of external facets, all of which demand detailed and verifiable data to meet the criteria set. The key drivers, including sustainability verification bodies, stock exchanges, governmental pressures, stakeholders, and consumers, and corporate customers, are shown in Figure 1. 


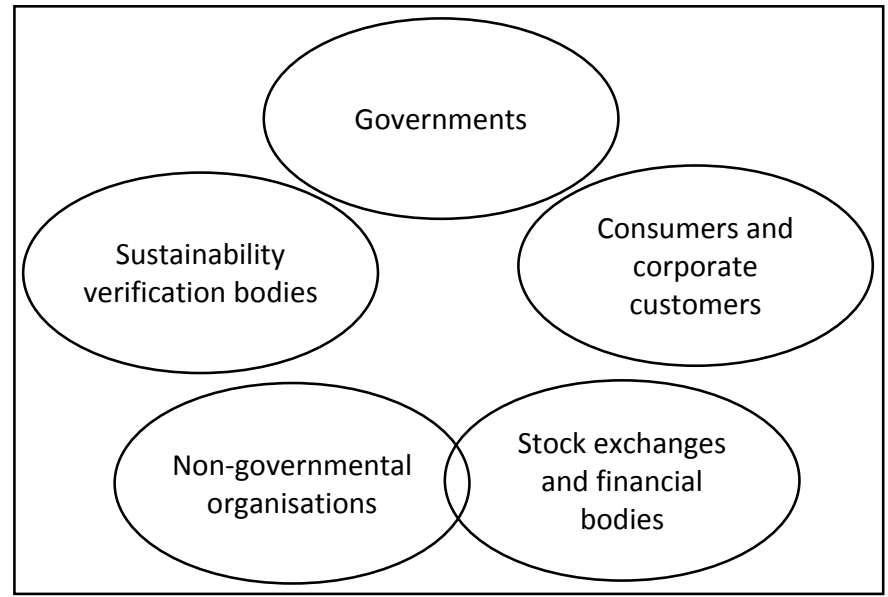

Figure 1. Key drivers on the demand of sustainability reporting.

\section{Sustainability Verification Bodies}

Companies now face verified auditing from external bodies to ensure that they are meeting clearly defined standards for the management of sustainability. These bodies include the Global Reporting Initiative (GRI), Carbon Disclosure Project (CDP), Clean Cargo Working Group (CCWG) and BSR, The Higgs Index, ISO 14001 and 26000 series among many others. It is notable that the latest versions of GRI Standards, which superseded GRI G4 Guidelines, and ISO14001: 2015 have placed emphasis on the consideration of operating practices along the supply chain. The most recent additions to internal sustainability standards and which increase emphasis to the auditing structure include the Sustainable Development Goals (SDG's) and Planet Mark.

\section{Stock Exchanges}

Increasingly, the stock exchanges have become key drivers in mandating sustainability reporting, expanding this practice throughout the supply chain to cover scope three suppliers. Transparency on sustainability impact throughout the corporate supply chain is becoming paramount. These mandates have led to increases in the reporting of sustainability data globally, similar to annual corporate financial reporting. Last October 2014, the Singapore Stock Exchange announced a sustainability-reporting mandate across all listed companies. In another example, in 2012, the Hong Kong Stock Exchange (HKEx) announced that companies could voluntarily provide sustainability reports with best practice recommendations (HKEx, 2012). Using the GRI Standard, or the previous GRI G4, as a framework, the HKEx aims to raise the standard in 2015 to a comply-or-explain semi-mandate requirement. The Hang Seng Index also launched a Corporate Sustainability Benchmark Index in 2010 to promote CSR in listed corporations.

\section{Governmental Pressures}

Governments are increasingly incorporating objectives in the reduction of $\mathrm{CO}_{2}$ emission targets as well as managing of the natural resources in their countries during their long-term plan. The China's 13th five-year plan focuses strongly on the reduction of greenhouse gas (GHG) emissions. These targets are creating "change management” process within manufacturers and shippers alike to manage their business processes in a more ethical fashion, whilst reducing negative impact on the environment. 


\section{Shareholders}

Increasingly corporate investment requires proof from firms that are conducting business in an environmental and corporate responsible manner. This has given rise to significant investment in tangible metrics and analytics surrounding Environmental and CSR based practices.

\section{Non-governmental Organisations}

Non-governmental organisations (NGOs) play a large role in raising awareness of a company's ethical and socially responsibly practices, which has been further elevated in recent years by the role of social media.

In addition to the key drivers, cost-saving philosophy is emphasized. Beyond stakeholder pressures are ethical companies continue to focus heavily on supply chain optimization as a means of reducing cost and increasing global efficiencies. The use of sustainability metrics is a key enabler to obtain transparency towards cost saving opportunities as well as optimal working practice strategies.

\section{Literature Review}

\section{Sustainability Reporting and Data Analytics}

Having examined the key-drivers in a company's sustainability practice along their supply chain, this paper now turns to provide a more thorough perspective on the role of data analytics and sustainability reporting. The measurement on sustainable development and the management of impact have been raised in the World Economic Forum in January 2015 (World Economic Forum, 2015). The opportunities and challenges on the impact assessment, goal setting, execution, sustainability reporting, and data analytics are discussed. Data analytics is described as an opportunity to provide new insights and visibility on the challenges of sustainable development. This includes the reporting and analysis in logistics and supply chain industry. The carbon emissions through the electricity consumption, warehouse operations, truck emissions, use of papers, carton boxes, and wooden pallets in logistics firms are expected to be measured, analysed, and reported regularly.

There are increasing concerns on how the logistics and supply chain corporations can benefit not only the employees and society but also improve the operations efficiencies, generating higher sales, and facilitating better data analytics with the use of sustainability reporting (Song, Cen, Zheng, Fisher, Liang, Wang, \& Huisingh, 2017; Burritt \& Schaltegger, 2014; Colicchia, Marchet, Melacini, \& Perotti, 2013; Lozano \& Huisingh, 2011). With the higher data transparency and visibility, the operation performance, including the sustainability statistics, can be better measured and evaluated. Bourlakis, Maglaras, Gallear, and Fotopoulos (2014) examined the sustainability performance of the Greek dairy chain. The key performance factors related to efficiency, flexibility, responsiveness, and product quality were assessed. Lee and $\mathrm{Wu}$ (2014) adopted a multi-methodology to integrate sustainability performance measurement into logistics and supply networks. The developed method supported the decision-making process on green practices of freight transport logistics. Ahi and Searcy (2014) proposed a mathematical model to assess sustainability in the supply chain after evaluating the dependent factors that impact the sustainability performance. The environmental, economic, and social dimensions of performance were evaluated. Ahi and Searcy (2015) further carried out an extensive literature review on the identification and analysis of the metrics on green and sustainable supply chain management. The most frequently used metrics are quality, air emissions, greenhouse gas emissions, water usage, energy use, and energy consumption. 
With the wide adoption of GRI, Chen, Tang, and Feldmann (2014) assessed the patterns and correlations between the levels of environmental management practices (EMPs) and financial performance of companies. It was found out that the number of EMPs has a strong correlation with the improvement on the innovation performance of various companies in Sweden, China, and India. Barkemeyer, Preuss, and Lee (2015) conducted hypothesis testing through a content analysis of 933 GRI sustainability reports of companies from seven sectors in 30 various countries. It is found that the output effectiveness of GRI was successfully developed through the dissemination of sustainability reporting from the companies. Fuente, García-Sánchez, and Lozano (2017) analysed the role of board of directors on social responsible information disclosure with reference to the GRI Standard related to CSR. A sample of 98 non-financial Spanish companies quoted on the Madrid Stock Exchange with 686 observations from the period of 2004 to 2010 was evaluated. It was found that corporate transparency on sustainability is directly linked to the independence and diversity of the board of directors in the companies.

Big data analytics in sustainability performance reporting requires the support of systems for better decision-making processes. Hallstedt, Ny, Robèrt, and Broman (2010) developed an approach to assess sustainability integration in a company's strategic decision system, based on established guidelines and a Bob Willard scale of sustainability integration. The performance of two companies is reviewed and found that there are potential ways to improve in the sustainability integration. Wognum, Bremmers, Trienekens, Van der Vorst, and Bloemhof (2011) explored the information systems that support the sustainability in food supply chains. The systems used assist personnel in the supply chain to communicate with their customers and make immediate decisions in daily operations. Pishvaee, Razmi, and Torabi (2012) addressed the problem of socially responsible supply chain network design under uncertain conditions by developing a bi-objective mathematical programming model with its objective functions on minimizing the total cost and maximizing the supply chain social responsibility. LINGO 9.0 optimization software is adopted to solve the proposed Robust possibilistic programming (RPP) model. Dubey, Gunasekaran, Childe, Papadopoulos, Luo, Wamba, and Roubaud (2017) investigated the effects of big data and predictive analytics on social and environmental performance with the use of variance based structural equation modelling. Other literature on sustainability performance modelling and analysis include Hassini, Surti, and Searcy (2012), Yercan and Yildiz (2011), and Bakshi and Fiksel (2003).

\section{Research Methodology}

\section{Methodology on Sustainability Performance Indicators and Data Analytics}

"Without measurement, you can't manage"-sustainable supply chain management is only possible through the incorporation of tools that support accurate, transparent, and verifiable analytics. The use of current standard tools serves only basic functions and simple operations, but the supply chains for most companies are too complicated to be supported without strong software system applications. These tools cover the whole supply chain spectrum down to supplier and sub-supplier level. The need for these products is essential to cover the key elements, such as energy consumption, fuel and fuel management, water, wastage, and air emission.

Furthermore the supply chain incorporates the need to evaluate transport and logistics modes and elements that support the distribution of products. The need to review impact assessment is also important when evaluating logistics impacts, this includes road freight mileage, air freight impact, ocean freight impact, vehicle efficiency, rail and barge operation, and route optimization to minimize fuel and carbon impact. A sustainability reporting and data analytics model for tackling complex supply chain infrastructure and problems 
is developed considering the resistance and barriers in capturing and measuring key sustainability data, refer to Figure 2.

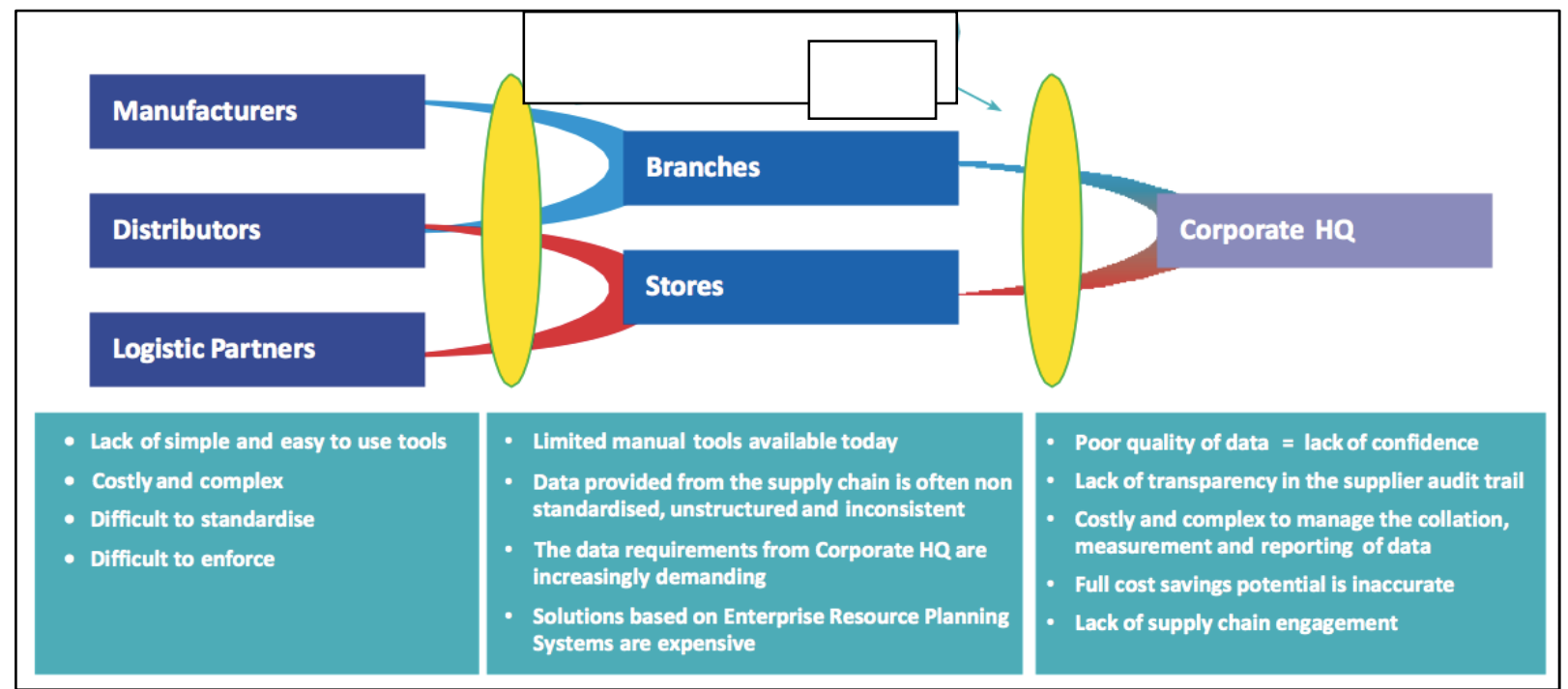

Figure 2. A sustainability reporting and data analytics model developed for tackling complex supply chain infrastructure and problems (Source: Turnkey Group, 2014b).

Capturing all the above-mentioned analytics requires investment at every element of the supply chain, and the need for detailed analytical tools to support all elements of the supply chain is necessary. To maximize the benefits and accuracy of sustainability reporting and analytics, the use of systems and software solutions that cover both governance reporting and supply chain infrastructure is essential. Equally important is the "buy in" from both global companies and their suppliers who service the supply chain, to incorporate best practices related to sustainability.

Multinational firms have continued to invest heavily in education and auditing of their supply chain partners. The issue has remained that additional workload and cost can be seen as de-motivation to incorporate sustainability practices. To overcome this, the use of simple, simplified data collection and analytics tools is essential to increase utilization in the supply chain as well as improve accuracy of reporting, leading to better decision making and cost reduction within the supply chain network. A system for sustainability reporting and data analytics in the supply chain operations is developed. One of the screenshots showing the sustainability performance indicators in the monitoring module is shown in Figure 3. The figure is displayed with demo data only considering the commercial purpose and data confidentiality.

The importance of verified data collection allows companies to make positive decisions on their business. This is incorporated through all members of the supply chain importing and uploading key sustainability data on energy, fuel, water, and wastage and allowing dynamic tools to calculate the impact of the supply chain. Thorough collection of data must also be consolidated into detailed dashboard reporting allowing companies to gain transparency of their entire supply chain through the collection of information from all their key suppliers. A dashboard for sustainability data analytics is developed and shown in Figure 4. These detailed data analytics are consolidated in the dashboard through the reporting of each of the company's key suppliers, leading to accurate strategic information which can be used to improve carbon and sustainability impact, as well as report directly to stakeholders and auditing parties. 


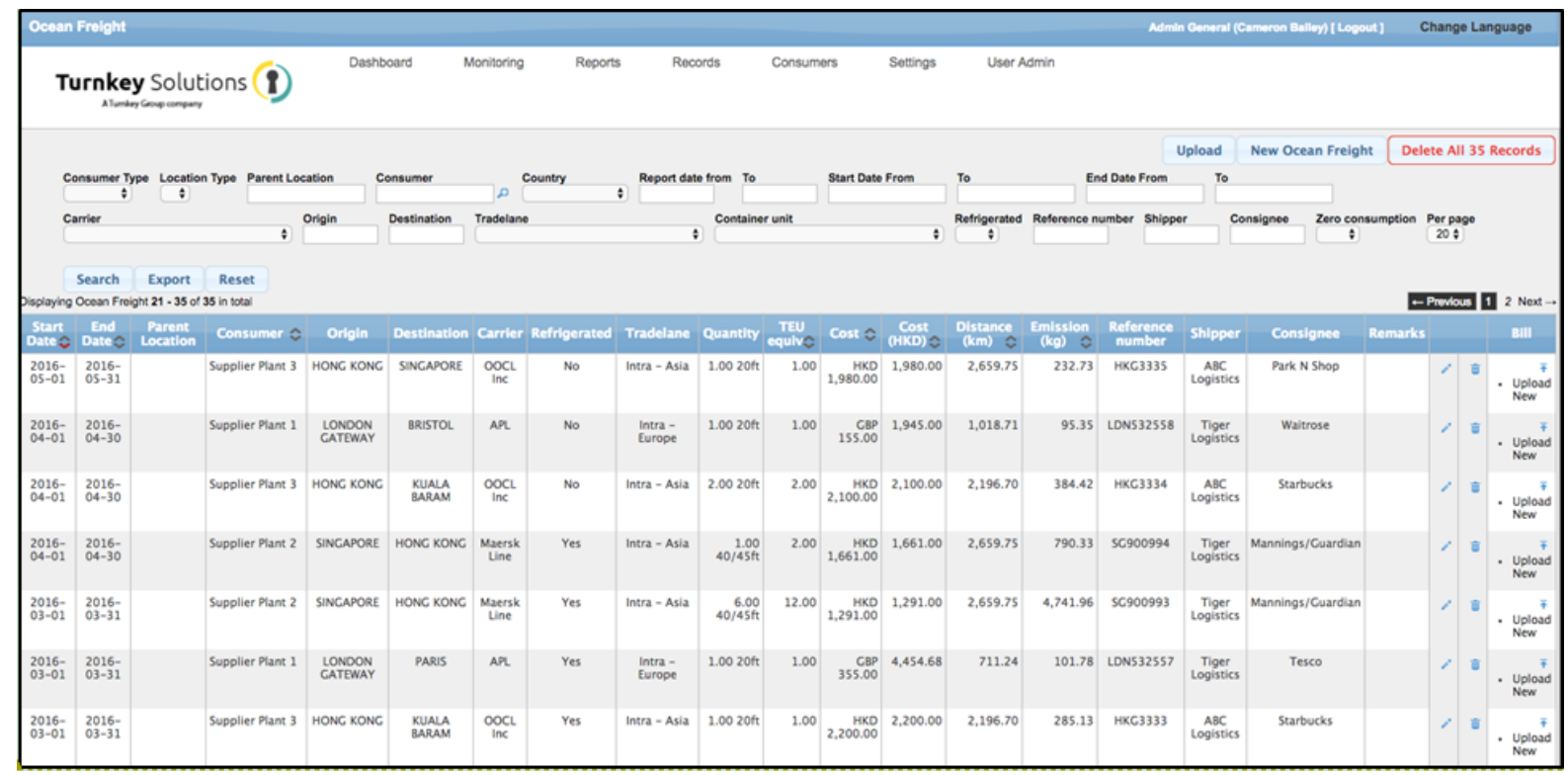

Figure 3. Sustainability data analytics in supply chain operations for ocean freight sector (demo data only).

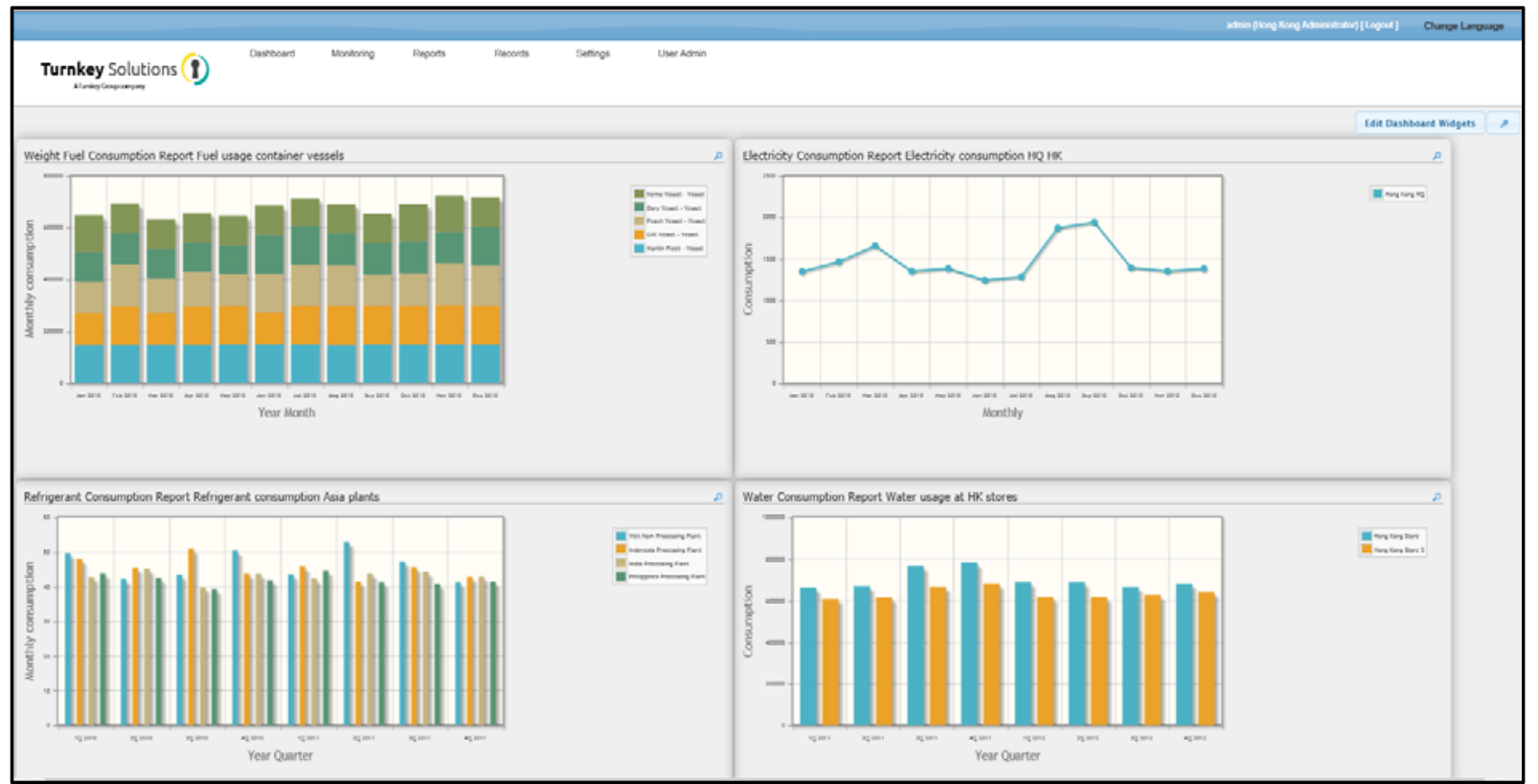

Figure 4. Sustainability dashboard for supply chain data analytics (Source: Turnkey Group, 2014a).

\section{Results and Discussions}

\section{Analysis on Supply Chain Sustainability in Maritime and Aviation}

Sustainability reporting supports corporations to analyse huge amount of complex supply chain data and make decisions with reference to the analyzed figures. Kuehne and Nagel, one of the world's leading logistics providers and ship liners, aims to the "Go Clean-Go Green" initiatives to reduce carbon emissions through vessel speed reduction, port handling, sailing schedule alignment, and equipment sharing (Van der Wal, 2011; 
Kuehne + Nagel, 2010). With the support of sustainability data, including vessel speed, carbon emissions, and fuel consumption, vessel operators can determine the optimal speed to minimize the cost and carbon emission. Maersk Line initiated slow steaming in their operations in selected vessels. Thirteen vessels in the same route have carried out economical speed consuming 10,000 MT fuel. Compared to the regular speed vessels consuming 12,000 MT fuel, the slow steaming vessels result a 16\% savings in carbon emission, from 37,000 MT $\mathrm{CO}_{2}$ of 20.5 knots to 31,000 MT CO 2 of 19 knots in vessel speed.

Besides enabling shippers to retrieve reliable data on their sea freight carbon footprint, Kuehne + Nagel launched carbon intelligence tool in 2009. The tool is a carbon management program designed to calculate carbon footprint of a customer in the supply chain, including warehousing and distribution. The tool aims to identify potential carbon reduction initiatives along supply chains. Two components are developed in the carbon intelligence tool, namely, global facility carbon calculator and global transport carbon calculator. The former one provides a tool to reduce resources consumption while the latter one measures carbon emissions and conducts carbon reporting. Siegle (2014) reported a study in the Department for Environment, Food and Rural Affairs (Defra UK) that two tonnes of freight cargo carrying 5,000 km by a small container vessel emit $150 \mathrm{~kg}$ $\mathrm{CO}_{2} \mathrm{e}$, compared to 6,605 $\mathrm{kg} \mathrm{CO}_{2} \mathrm{e}$ if the freight cargo is carried out by air for the same distance. Thus, the decision on the mode of transportation for a cargo affects not only operation costs but also the carbon emission in the trip of the cargo. Thus, the carbon intelligence model in Kuehne + Nagel serves as an intelligence dashboard for data analytics and decision support tool.

With the endorsement of government and support of its airport business partners, Airport Authority of Hong Kong (AAHK) pledged to develop its airport to the greenest airport in the world. A multi-stakeholder model is developed as an environmental strategy in achieving the goal by increasing its influence beyond its control regime and guiding various stakeholders, who are not under direct responsibility of AAHK, to realize the goal. This model leverages 1,700 staff in AAHK against airport outsourced business partners of 73,000 staff in accomplishing the carbon reduction programme as an environmental initiative goal. As $60 \%$ of greenhouse gas emissions are generated by airport business partners while $40 \%$ are from the airport, thus, the AAHK needs to develop sustainable multi-stakeholder infrastructure to accelerate airport-wide GHG emissions reduction.

Throughout the carbon reduction programme, AAHK achieved a $25.6 \%$ reduction in carbon intensity in 2015, compared to 2008 baseline, surpassing the original target of reducing $25 \%$ a carbon intensity by $25 \%$ set in 2010. AAHK, together with 53 airport business partners in 2016, further targeted to reduce airport-wide carbon emissions by $10 \%$ from 2015, with the baseline of 2020. The environmental performance monitoring system, online carbon audit system (CAS), allows all airport business partners, including airlines, airline caterers, government departments, cargo handlers, and ground service providers, in inputting carbon emissions-related data, calculating their carbon performance, and analysing their trends and sustainability performance results.

Swire, is a highly diversified global group with business including property, aviation, beverages and food chain, marine services, trading and industrial sector. Sustainable development has been always one of the key objectives in Swire Pacific, with a group-wide environmental sustainability strategy set in 2016, including a target of 2\% fuel efficiency improvement per annum from 2009 to 2020 in Cathay Pacific, Net Zero Environmental Impact initiatives in Swire Pacific Offshore Group (SPO), and participation on greenhouse gas protocol assessment in Swire Beverages. The assessment in Swire Beverage includes the analysis of product carbon footprint on Coca-Cola drinks. The total carbon emission from Beverage Division is 198,769 ton $\mathrm{CO}_{2} \mathrm{e}$ in 
2012 (Swire Pacific, 2015). To continue mitigating carbon emissions and improving product carbon footprint performance, Swire Beverages has dedicated to carrying out emission reduction initiatives on packaging design, fleet configuration, and energy efficiency management. Handling vast amount of sustainability data within the Swire Group for sustainability reporting and performance monitoring, the methodology of capturing, visualising, analysing, and monitoring data on customer, own operation processes and supplier along the company dynamic supply chain infrastructure is becoming more important in the era of big data analytics.

\section{Conclusion}

Data transparency, reporting, and analytics in sustainability are increasing important, especially in dynamic supply chain logistics operations. Various societal stakeholders, including governments, sustainability verification bodies, NGO, HKEx, customers, drive ship liners, truck operators, airlines, and logistics firms to improve their operations that impact the environment, social governance, and corporate social responsibility. This paper reviews the current importance of the societal stakeholders in driving the logistics firms to report their sustainability activities and initiate programmes to reduce carbon emissions. A sustainability reporting and data analytics model is developed to facilitate and support supply chain practitioners in decision making process. The model has been further developed as a dashboard and applied in a maritime supply chain firm. Analysis cases have been reviewed illustrating the importance of sustainability data analytics in assisting the decision-making process on complex supply chain and logistics operations. Future development on the sustainability performance and data analytics tool is recommended, including additional intelligent features and functionalities to identify correlation of significant factors towards operation efficiencies in a corporation.

\section{References}

Ahi, P., \& Searcy, C. (2014). Assessing sustainability in the supply chain: A triple bottom line approach. Applied Mathematical Modelling.

Ahi, P., \& Searcy, C. (2015). An analysis of metrics used to measure performance in green and sustainable supply chains. Journal of Cleaner Production, 86, 360-377.

Bakshi, B. R., \& Fiksel, J. (2003). The quest for sustainability: Challenges for process systems engineering. AIChE Journal, 49(6), 1350-1358.

Barkemeyer, R., Preuss, L., \& Lee, L. (2015). On the effectiveness of private transnational governance regimes-Evaluating corporate sustainability reporting according to the Global Reporting Initiative. Journal of World Business, 50(2015), 312-325.

Bourlakis, M., Maglaras, G., Gallear, D., \& Fotopoulos, C. (2014). Examining sustainability performance in the supply chain: The case of the Greek dairy sector. Industrial Marketing Management, 43(1), 56-66.

Burritt, R., \& Schaltegger, S. (2014). Accounting towards sustainability in production and supply chains. The British Accounting Review, 46(4), 327-343.

Chen, L., Tang, O., \& Feldmann, A. (2014). Applying GRI reports for the investigation of environmental management practices and company performance in Sweden, China and India. Journal of Cleaner Production.

Colicchia, C., Marchet, G., Melacini, M., \& Perotti, S. (2013). Building environmental sustainability: Empirical evidence from logistics service providers. Journal of Cleaner Production, 59, 197-209.

Dubey, R., Gunasekaran, A., Childe, S. J., Papadopoulos, T., Luo, Z., Wamba, S. F., \& Roubaud, D. (2017). Can big data and predictive analytics improve social and environmental sustainability? Technological Forecasting and Social Change.

Fuente, J. A., García-Sánchez, I. M., \& Lozano, M. B. (2017). The role of the board of directors in the adoption of GRI guidelines for the disclosure of CSR information. Journal of Cleaner Production, 141, 737-750.

Hallstedt, S., Ny, H., Robèrt, K. H., \& Broman, G. (2010). An approach to assessing sustainability integration in strategic decision systems for product development. Journal of Cleaner Production, 18(8), 703-712. 
Hassini, E., Surti, C., \& Searcy, C. (2012). A literature review and a case study of sustainable supply chains with a focus on metrics. International Journal of Production Economics, 140(1), 69-82.

Hong Kong Exchanges and Clearing Limited (HKEx). (2012). 2012 corporate social responsibility report.

Kuehne + Nagel. (2010). Sustainability in container shipping. Go clean-Go Green—Go with Kuehne + Nagel.

Lee, K. H., \& Wu, Y. (2014). Integrating sustainability performance measurement into logistics and supply networks: A multi-methodological approach. The British Accounting Review, 46(4), 361-378.

Lozano, R., \& Huisingh, D. (2011). Inter-linking issues and dimensions in sustainability reporting. Journal of Cleaner Production, 19(2), 99-107.

Pishvaee, M. S., Razmi, J., \& Torabi, S. A. (2012). Robust possibilistic programming for socially responsible supply chain network design: A new approach. Fuzzy Sets and Systems, 206, 1-20.

Siegle, L. (2014). How ethical is shipping goods by sea? The Guardian. (last accessed on 29 April 2015: http://www.theguardian.com/environment/2014/nov/02/environmental-impact-of-shipping-goods)

Song, M., Cen, L., Zheng, Z., Fisher, R., Liang, X., Wang, Y., \& Huisingh, D. (2017). How would big data support societal development and environmental sustainability? Insights and practices. Journal of Cleaner Production, 142, 489-500.

Swire Pacific. (2015). CDP 2015 climate change 2015 information request.

Turnkey Group. (2014a). Turnkey Solutions [software]. Hong Kong.

Turnkey Group. (2014b). [Information slides on Turnkey solutions sustainability software product]. Sales Concept.

Van der Wal, T. (2011). Reducing $\mathrm{CO}_{2}$ emissions for Kuehne + Nagel Helmond.

World Economic Forum. (2015). Data-driven development pathways for progress.

Wognum, P. N., Bremmers, H., Trienekens, J. H., Van der Vorst, J. G., \& Bloemhof, J. M. (2011). Systems for sustainability and transparency of food supply chains_Current status and challenges. Advanced Engineering Informatics, 25(1), 65-76.

Yercan, F., \& Yildiz, T. (2011). Environmental reporting of industrial and supply chain business processes within the context of sustainable development. Verslas: teorijairpraktika, (1), 5-14. 